\title{
Development and Performance Evaluation of a Grain Probe Moisture Meter for Paddy
}

\author{
Arlene C. Joaquin, Maria Elizabeth V. Ramos, and Romualdo C. Martinez
}

\begin{abstract}
A frequency-based capacitance type grain probe moisture meter was developed, as a low-cost alternative tool for accurate and rapid moisture content measurement of paddy grains in bags. The prototype unit consisted of a standard grain probe; a 100-gram capacity test chamber; a grain selector panel for overall control and measurement; and a handle for ease of sampling. Calibration models between frequency and dry oven method moisture contents were established and validated with a relatively high coefficient of determination (R2) of 0.94 . Laboratory and actual field testing conducted between moisture content readings of grain probe moisture meter and standard reference oven method resulted to mean absolute error of 0.24 . Likewise, field testing results conducted revealed a mean percentage error of 3.9 percent, an indication of a highly acceptable level of accuracy based on standards set by the National Institute of Standard and Technology (NIST) and United States Department of Agriculture - Grain Inspection, Packers and Stockyards Administration (USDA-GIPSA). Initial fabrication cost of the prototype unit grain probe moisture meter was approximately US\$ 100.00 which is very competitive with existing imported popular brands of grain moisture meters with investment cost ranging from US\$ 750.00 to above US\$ 4,000.00 The prototype unit grain probe moisture meter has the advantage of simultaneously performing grain sampling and moisture content determination. Likewise, the grain probe meter can potentially save time and effort in moisture assessment and most importantly ensure the procurement of quality grains, ease in MC monitoring of stocks during storage and MC validation before storage and milling.
\end{abstract}

Index Terms-Capacitance, frequency-based, moisture, meter, paddy.

\section{INTRODUCTION}

Moisture content and purity are primary quality factors which form part of the basis of payment and are therefore properly determined at every point of postharvest handling. Moreover, accuracy of moisture content level in a product is very critical especially when transactions are based on weight Small errors in measurement can have significant consequences [1].

In the Philippines, private traders-millers and the National Food Authority (NFA) usually used only two parameters in pricing grains; moisture content and purity or cleanliness [2]. The Equivalent Net Weight Factor (ENWF) table, derived from moisture content level of grains was used by NFA in the determination of paddy procurement price.

The most common and practical method of moisture

Manuscript received May 3, 2019; resvised July 12, 2019.

The authors are with the Agricultural Mechanization Division (AMD) of the Philippine Center for Postharvest Development and Mechanization (PHilMech). Philippine (e-mail: arlyn1111@gmail.com). content determination in the country is empirical method without using any device. The method involves nibbling of grains and crushing between fingers. Others rely on the smell of dull or sharp rattle produced by shaking a few grains in a box. While this practice was a popular choice among our local farmers, traders and processors; these methods based on individual experience, do not give a true objective measurement, but estimate the degree of moisture by subjective sensory perception [3]. Moreover, such method is prone to abuse. The classifier may misclassify the moisture content of the grain to the disadvantage of the farmer and other key players on the grain trading industry.

Similarly, a typical grain handling operation in the Philippines is not possible without the use of a sampling probe, locally known to the industry as "buriki". It is a tool used mostly by agents and classifiers to collect grain samples like paddy, rice and corn from randomly selected bags. Collected samples using buriki were initially assessed for purity, damaged and discolored kernels by ocular inspection. Moisture content is then assessed using empirical method or if available, moisture meters. This method besides being subjective entails double handling and in most cases prolongs procurement operation. Buriki is also used to facilitate periodic monitoring of stored grains [1], [4]

Cognizant of this, the Philippine Center for Postharvest Development and Mechanization (PHilMech) attempted to integrate a moisture sensing mechanism to the popular tool, buriki and came up with a prototype unit grain probe moisture meter. It was aimed at providing a less- expensive alternative tool to address the subjectivity and long process of empirical method of moisture content determination of grains in bags. The prototype unit comprised of a standard probe (buriki), a 100-gram capacity test chamber, a menu panel for overall control and measurement and provided with a handle for ease of sampling. It featured a micro-controller based processor and a 7-segment 3-digit LCD screen. Computer Aided Design (CAD) drawing of the prototype unit is shown in Fig. 1 while Fig. 2 shows the actual picture of the prototype unit grain probe moisture meter. It was initially designed to measure paddy.

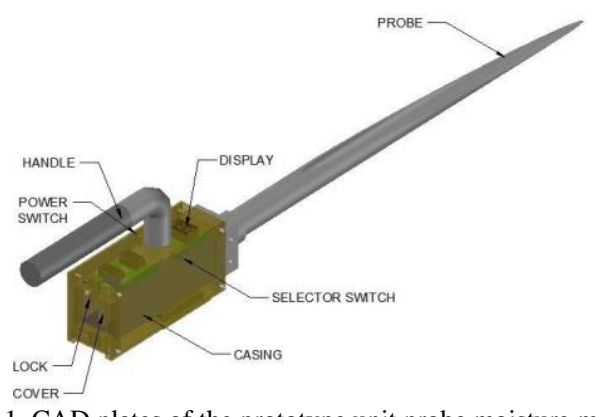

Fig. 1. CAD plates of the prototype unit probe moisture meter. 


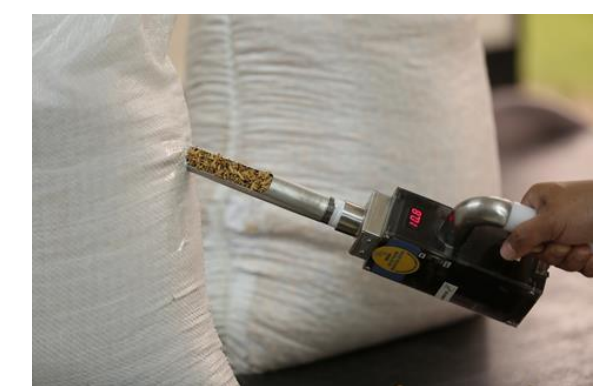

Fig. 2. The prototype unit grain probe moisture meter.

Calibration tests as shown in Fig. 3 conducted between frequency readings and standard oven moisture content measurements of paddy yielded strong linear relationship. Calibration model were established with relatively high correlation of determination (R2) of 0.94 and a comparatively low standard error of estimate (SEE) of 0.87 ; an indication of excellent fit of the prototype system design.

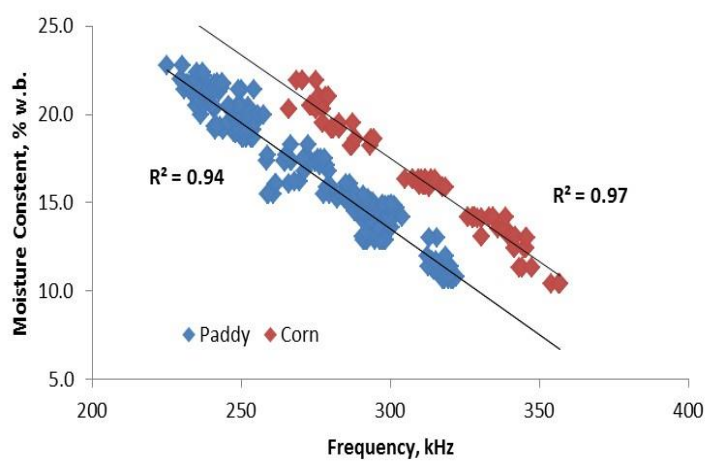

Fig. 3. Calibration data generated from laboratory experiments for paddy and corn.

Preliminary validation tests have demonstrated that the calibration models of the prototype unit grain probe moisture meter were adequate in predicting moisture content of paddy grains. Likewise, operational and functional requirement were initially evaluated in a farmers' cooperative in Nueva Viscaya and resulted to positive reviews and recommendations of the potential end users. This paper presents the validation tests and field testing results to evaluate the technical performance of the developed prototype unit grain probe moisture meter in actual field conditions.

\section{Methodology}

\section{A. Description of the Prototype Grain Probe Moisture Meter}

The prototype unit grain probe moisture meter comprised of a standard probe; a constant 100-gram capacity test chamber where samples to be measured are placed; a sliding power switch and grain selector for overall control and measurement. It was also provided with a handle for ease of handling. It has a total length of about $630 \mathrm{~mm}, 42 \mathrm{~mm}$ width and aggregate weight of 730 grams without load (Fig. 4).

\section{B. Technology Performance Evaluation of Prototype Grain Probe Moisture Meter}

This activity was conducted to establish the operating characteristics of the prototype grain probe moisture meter. Procedures were divided into two stages: laboratory experiment and actual field testing

1) Laboratory experiments of the prototype grain probe moisture meter

The prototype unit grain probe moisture meter was evaluated in a controlled laboratory setting for precision, accuracy and operating range of temperature as shown in Fig. 6. Measured moisture contents were compared to oven-dried samples based on ASAE Standards [5] moisture content determination method. A total of 30 and samples with different moisture content levels were used as test samples. Moisture content of the paddy samples ranged from 8.90 percent to 18 percent, covering the critical moisture content level of 14 percent.
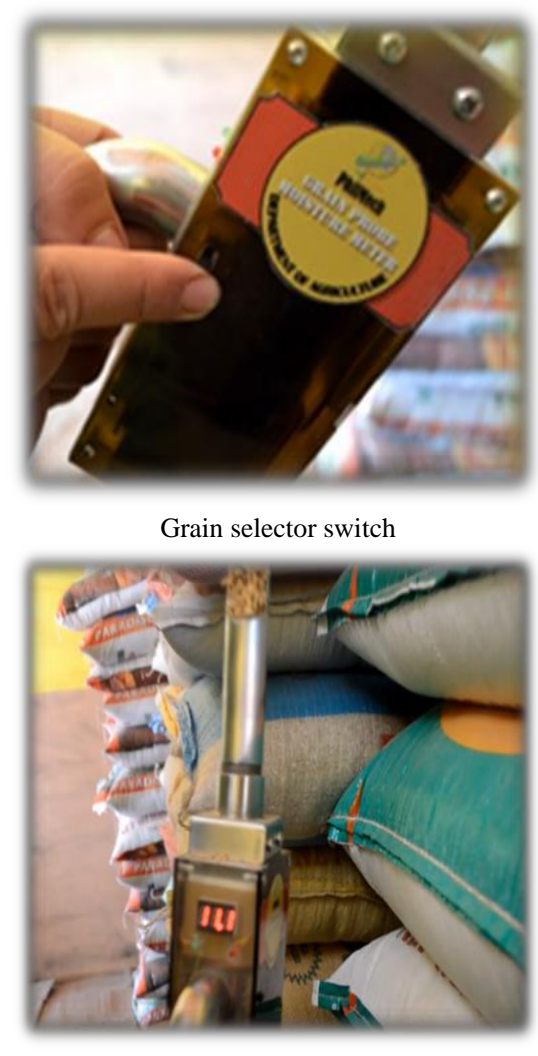

LCD display

Fig. 4. Salient features of the prototype unit grain probe moisture meter.

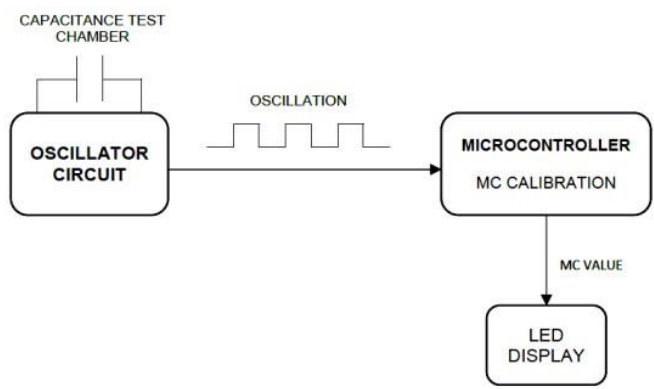

Fig. 5. Functional block diagram of the prototype unit grain probe moisture meter

Precision and accuracy were tested using 16 levels of moisture contents based on the provisions of the National Institute for Standards Technology (NIST) Handbook 44 [6]. The provision indicated a test of at least three (3) replicates per sample and at least two (2) levels of moisture contents for 
a testing to be standard. On the other hand, Unified Grain Moisture Algorithm (UGMA) of the United States Department of Agriculture (USDA) requires an average difference for at least six (6) samples [7], [8] for which this project complied upon. Each sample with varying moisture contents was measured in 10 replicates. Precision was computed using mean error, range and standard deviation (Std. Dev). Range was expressed by the difference between the highest and lowest moisture content readings of the grain probe moisture meter with the below equation (1) while standard deviation was computed for all population using standard equation of Windows Excel software.

$$
\text { Range }=\mathrm{MC}_{\max }-\mathrm{Mc}_{\min }
$$

Where

$$
\begin{aligned}
\mathrm{MC}_{\max }= & \text { highest moisture content value attained by the } \\
& \text { grain probe moisture meter within the } 10 \\
& \text { replicates, } \%
\end{aligned}
$$

$\mathrm{MC}_{\min }=$ lowest moisture content value attained by the grain probe moisture meter within the 10 replicates, $\%$

On the other hand, percentage error as a function of accuracy was measured using the below equation as cited by Hassen [9]:

$$
\left.\% \text { Error }=\frac{\text { ABS (Reference MC }- \text { Measured MC }}{\text { Reference MC }} \times 100 \%\right)
$$

where:

Reference $\mathrm{MC}=\mathrm{MC}$ reading using oven-dry method,

$$
\text { \%w.b. }
$$

Measured $\mathrm{MC}=\mathrm{MC}$ readings using grain probe $\mathrm{MC}$ meter,

$$
\%
$$

Effects of temperature as well as purity of the samples against accuracy were also observed to establish the operating range workable for the prototype unit grain probe moisture meter. Since no conditioning chamber is available to vary the temperature, the observations were limited to the actual temperature readings at the time of each testing.

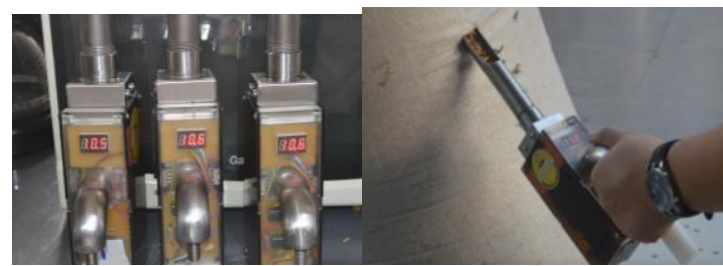

Fig. 6. Actual laboratory experiments of the prototype unit grain probe moisture meter.

\section{2) Actual field testing of the prototype grain moisture meter}

A total of ten cooperators were initially selected for the project. Five of the listed potential cooperators were from the National Food Authority (NFA); two from Isabela (Santiago and Echague), one each from Cabanatuan City and two from
Pangasinan (Binalonan and Lingayen).Also, two trader-rice millers were selected from Pangasinan (Bayambang, Mangatarem) and Bulacan (San Rafael, Bocaue), respectively. Only one farmer's cooperative (Nueva Vizcaya) was selected which was also engaged in grains trading and rice milling. However, due to limited samples and procurement operations, only three cooperators with sufficient data available were considered in the technical evaluation presented in this report but recommendations and observations of the other three (3) cooperators were all considered. Northern Luzon Grains Processing Center (NGPC) in Echague, Isabela; a cooperative in Nueva Viscaya and a ricemiller-trader in Bulacan provided the data herein considered.

Technical performance evaluation in terms of accuracy and precision were conducted based on the actual utilization data provided by the cooperators. A trained classifier in charge of procurement operations were selected and trained on the operations prior to the testing. Data sheets were given to cooperators to record comparative moisture readings between the prototype unit grain probe moisture meter and their existing MC meters. A conversion table of the cooperators' existing MC meter readings to equivalent oven moisture content were established before the testing and served as basis of evaluation. Aa total of 25, 15 and 6 moisture content readings were gathered and evaluated for Bulacan, Isabela and Nueva Viscaya respectively. Equations used for the computation were the same as the equations used for laboratory testing.

\section{RESULTS}

\section{A. Precision and Accuracy of the Prototype Unit Grain Probe Moisture Meter}

Fig. 7 shows the comparison of moisture content readings of paddy samples between the prototype unit grain probe moisture meter and oven-dried paddy samples. In general, it was observed that the moisture meter readings of the grain probe moisture meter followed closely the moisture content determined by air oven method.

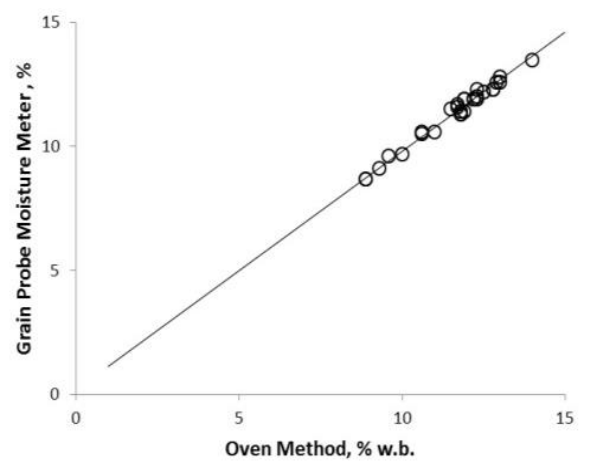

Fig. 7. Comparison of paddy moisture content readings between oven method and grain probe moisture meter.

Likewise, test results given in Table I indicated the technical viability of the grain probe moisture meter tested for paddy samples with 16 levels of moisture contents. Range as a function of precision was computed to be 0.16 percent while mean error and percentage error was measured to be 
0.24 percent and 2.0 percent, respectively and within the 0.8 percent mean error and 5 percent error standards set [6], [7].

TABLE I: LABORATORY TEST RESULT OF PADDY MOISTURE CONTENT READINGS BETWEEN REFERENCE OVEN METHOD AND THE PROTOTYPE UNIT GRAIN PROBE MOISTURE METER

\begin{tabular}{|c|c|c|c|c|c|}
\hline \multicolumn{2}{|c|}{ Moisture Content } & \multirow[b]{2}{*}{$\begin{array}{c}\text { Absolute } \\
\text { Error }\end{array}$} & \multirow[b]{2}{*}{$\begin{array}{l}\% \text { Error } \\
\text { (Accuracy) }\end{array}$} & \multirow[b]{2}{*}{$\begin{array}{l}\text { Std. } \\
\text { Dev. }\end{array}$} & \multirow[b]{2}{*}{$\underline{\text { Range }}$} \\
\hline $\begin{array}{l}\text { Oven, } \\
\text { \% w.b. }\end{array}$ & $\begin{array}{c}\text { Probe } \\
\text { Meter, \% } \\
\end{array}$ & & & & \\
\hline 17.40 & 17.10 & 0.30 & 1.72 & 0.30 & 0.25 \\
\hline 14.00 & 13.50 & 0.50 & 3.57 & 0.50 & 0.21 \\
\hline 13.00 & 12.70 & 0.30 & 2.31 & 0.14 & 0.20 \\
\hline 12.90 & 12.60 & 0.30 & 2.33 & 0.30 & 0.30 \\
\hline 12.80 & 12.30 & 0.50 & 3.91 & 0.00 & 0.00 \\
\hline 12.50 & 12.20 & 0.30 & 2.40 & 0.30 & 0.30 \\
\hline 12.30 & 12.15 & 0.15 & 1.22 & 0.21 & 0.14 \\
\hline 12.20 & 11.90 & 0.30 & 2.46 & 0.00 & 0.30 \\
\hline 11.70 & 11.65 & 0.05 & 0.43 & 0.07 & 0.10 \\
\hline 11.50 & 11.50 & 0.00 & 0.00 & 0.00 & 0.00 \\
\hline 11.00 & 10.60 & 0.40 & 3.64 & 0.40 & 0.14 \\
\hline 10.60 & 10.55 & 0.05 & 0.47 & 0.07 & 0.10 \\
\hline 10.00 & 9.70 & 0.30 & 3.00 & 0.30 & 0.30 \\
\hline 9.60 & 9.60 & 0.00 & 0.00 & 0.00 & 0.00 \\
\hline 9.30 & 9.10 & 0.20 & 2.15 & 0.20 & 0.20 \\
\hline \multirow[t]{4}{*}{8.90} & 8.70 & 0.20 & 2.25 & 0.00 & 0.00 \\
\hline & Average & 0.24 & 1.99 & 0.17 & 0.16 \\
\hline & Min & 0.00 & 0.00 & 0.00 & 0.00 \\
\hline & $\operatorname{Max}$ & 0.50 & 3.91 & 0.50 & 0.30 \\
\hline
\end{tabular}

* average of 10 replicates

\section{B. Effect of Temperature and Purity on the Accuracy of the Prototype Unit Grain Probe Moisture Meter}

\section{1) Temperature}

Temperature is one critical factor when using capacitance sensors [10]-[12]. A test was conducted to evaluate the effect of temperature to the performance of the grain probe moisture meter. With actual temperature ranging from $21.8 \mathrm{oC}$ to $32.7 \mathrm{oC}$, accuracy of the grain probe moisture meter was not significantly affected as indicated in the regression analysis conducted between temperature readings and mean error of measurements. Results showed a very low R2 of 0.20 indicating very low relationship between temperature and accuracy. Likewise, a $\mathrm{P}$ value of 0.28 was computed indicating no significant relationship between temperature readings and mean error of measurement of moisture contents at 5 percent level of confidence. Moreover, the mean error as well as the percentage error is way below the 0.8 percent moisture reading and 5 percent minimum errors based on NIST standards [6]. These findings were consistent to the observation of Stubsgaard [12] that no temperature correction might be needed within the temperature range of $10 \mathrm{oC}$ to $30 \mathrm{oC}$.

\section{2) Purity of grain samples}

Accuracy of the grain probe moisture meter was also tested with different levels of purity of paddy samples. Actual samples measured for moisture content reading were the samples used for the test. Spread of data generated for 35 measurement points as shown in Fig. 8 seemed to indicate an acceptable level of accuracy for purity level ranging from 94 percent to 100 percent. The spread of mean error of measurement against temperature readings were all within the acceptable mean error of 0.8 percent. A more consistent accuracy however was observed at purity levels of 99 percent and higher. The observed mean error that tended to be negative values at lower purity range and positive values at higher purity range seemed to indicate significant effect but results of regression analysis has proven otherwise with an $\mathrm{R} 2$ of 0.03 and $\mathrm{P}$ value of 0.32 .

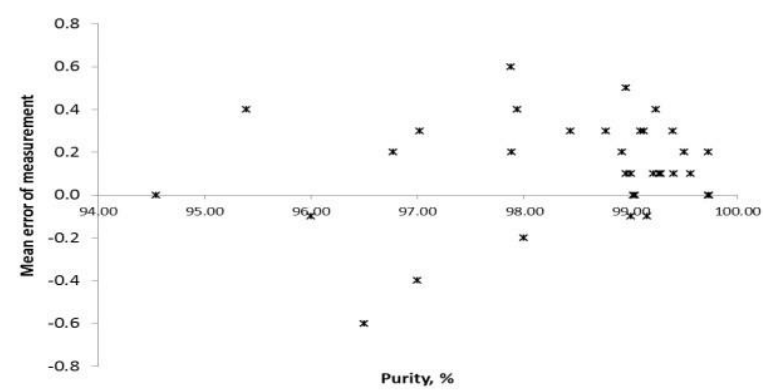

Fig. 8. Effect of paddy purity level against mean error of measurement.

Based from the tests conducted, technical specifications of the prototype unit grain probe moisture meter were established and is given in Table II. The prototype unit grain probe moisture meter was initially calibrated for paddy with moisture content range of 8 percent to 34 percent with mean measurement error of 0.24 percent and percentage error of 2.0 percent.

TABLE II: TECHNICAL SPECIFICATIONS OF THE GRAIN PROBE MOISTURE METER

\begin{tabular}{|c|c|c|}
\hline Particulars & Parameters & Standard $^{1}$ \\
\hline Measuring principle & Capacitance & \\
\hline Applications & Paddy and corn grains & \\
\hline Measuring range, $\%$ & 8 to 34 & Varies \\
\hline Resolution & $0.10 \%$ & $0.10 \%$ (commercial) \\
\hline $\begin{array}{ll}\text { Operating } & \text { temp. } \\
\text { range, }{ }^{\circ} \mathrm{C} & \\
\end{array}$ & $21-33$ & $10-40^{\circ} \mathrm{C}, \min$ \\
\hline $\begin{array}{ll}\text { Moisture } & \text { respond } \\
\text { speed }\end{array}$ & $<5$ seconds & Not indicated \\
\hline Mean error & $\pm 0.24 \%$ Mean MC & $\pm 0.8 \%$ \\
\hline$\%$ error & $2.0 \%$ Mean MC & $5 \%$ \\
\hline Sample size & 100 grams & $100 \mathrm{~g}$ or 400 seeds \\
\hline Type of display & $\begin{array}{lll}\text { 3-digit } & 7 & \text { segment } \\
\text { display } & & \\
\end{array}$ & Varies \\
\hline Power supply & 3.7V lithium-ion & Varies \\
\hline \multicolumn{3}{|l|}{ Unit size, $\mathrm{mm}$} \\
\hline w/ probe & $630 \times 50.60 \times 70.40$ & \\
\hline w/out probe & $180 \times 50.60 \times 70.40$ & \\
\hline
\end{tabular}

\section{Actual Field Testing of the Prototype Unit Grain Probe Moisture Meter}

Shown in Table III is the summarized field testing results from the three cooperators in Bulacan, Isabela and Nueva Viscaya. Results revealed comparable findings with the laboratory validation in terms of precision and accuracy. Nueva Viscaya test result was found to have the lowest mean error of 0.52 percent and percentage error of 5.6 percent that might have caused by the least number of measurements yet 
widest ranges of moisture contents. On the other hand, test result in Bulacan yielded the highest accuracy, with mean error of 0.27 percent and percentage error of 1.90 percent. The said test site has the most number of measurements completed. All three however, conformed to the required tolerances and allowable measurement errors set [6].

TABLE III: TECHNICAL SPECIFICATIONS OF THE GRAIN PROBE MOISTURE METER

\begin{tabular}{cccccc}
\hline $\begin{array}{c}\text { Testing } \\
\text { Site }\end{array}$ & MC Level $^{1}$ & $\begin{array}{c}\text { Mean } \\
\text { Error }\end{array}$ & $\begin{array}{c}\text { \%Error } \\
\text { (Accuracy) }\end{array}$ & Std. Dev. & Range \\
\cline { 1 - 4 } Bulacan & 10.0 to 14.0 & 0.27 & 1.90 & 0.02 & 0.23 \\
$\begin{array}{c}\text { Isabela } \\
\text { Nueva } \\
\text { Viscava }\end{array}$ & 7.9 to 12.0 & 0.20 & 4.10 & 0.27 & 0.44 \\
\cline { 1 - 1 } & 8.1 to 23.6 & 0.12 & 5.60 & 0.37 & 0.52 \\
\cline { 1 - 2 } & Average & $\mathbf{0 . 2 0}$ & $\mathbf{3 . 9 0}$ & $\mathbf{0 . 2 2}$ & $\mathbf{0 . 2 9}$ \\
\hline
\end{tabular}

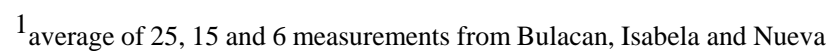
Viscaya, respectively

\section{SUMmARY AND CONCLUSIONS}

A frequency-based capacitance-type grain probe moisture meter was designed, developed and evaluated for accurate and rapid moisture content measurement of paddy grains in bags. Calibration models between frequency and moisture contents were established and validated with a relatively high correlation of determination (R2) of 0.94. Likewise, field testing results in Bulacan, Isabela and Nueva Viscaya revealed a measurement error of 0.20 percent and percentage error of 3.90 percent, an indication of acceptable level of accuracy and compliance with existing standards set by NIST [6], a reputable institution under the United States Department of Commerce which main task is to promote equitable standards worldwide.

Initial fabrication cost of the prototype unit grain probe moisture meter was approximately US\$ 100.00 which is very competitive with existing imported popular brands of grain moisture meters with current market cost ranging from US\$ 750.00 to above US\$ 4,500.00. In addition, the prototype unit grain probe moisture meter has the advantage of simultaneously performing grain quality sampling and moisture content determination.

\section{CONFLICT OF INTEREST}

The authors herein declare that the submitted research work was carried out with no conflict of interest.

\section{AUTHOR CONTRIBUTIONS}

The main author, ACJoaquin led the conduct of the research, design, field performance evaluation, data analysis and technical writings. MEVRamos provided the needs assessment through surveys and interviews. RCMartinez on the otherhand, provided technical advice and expertise to the research. This final version of the paper is duly approved by all the authors.

\section{ACKNOWLEDGMENT}

The authors wish to extend their sincerest appreciation to a number of people who have contributed to attain the objectives of this research. To Mr. Elvin B. Santos for his valuable contribution in the programming and circuit design. To the officers and staff of Nueva Vizcaya Multi-Purpose Cooperative (NVAKMPC) Inc., for allowing the project team to conduct various experiments and access to sufficient supplies of paddy samples. Our sincerest gratitude to the National Food Authority (NFA, in selected warehouses in the Philippine for allowing their various paddy stocks as testing materials and for unselfishly sharing the information needed. Also, to various grain traders, processors, farmers and farmer- cooperatives in Bulacan, Isabela, Nueva Ecija, Nueva Viscaya and Pangasinan for their time and generosity. And foremost, to Almighty God who is the source of wisdom and inspiration, which enabled the authors to sustain their commitment to undertake this research work.

\section{REFERENCES}

[1] R. L. Sampang, "Integrated commodity and pest management in grain storage," in Proc. Selected Papers from the Regional Training Course on Integrated Pest Management Strategies in Grain Storage Systems, FAO in Collaboration with NAPHIRE, 1992.

[2] National Food Authority. (April 2019). [Online]. Available: http://nfa.gov.ph/buying-selling-price

[3] R. L. Semple, P. A. Hicks, J. V. Lozare, and A. Castermans, "A Training Manual for application in humid tropical storage systems," Food and Agriculture Organization of the United Nations, 1988.

[4] M. E. V. Ramos and A. C. Joaquin, "Needs Assessment on moisture content determination of selected grains," Philippine Center for Postharvest Development and Mechanization, 2015

[5] ASAE S352.2, "Moisture measurement - Unground grain and seeds," American Society of Agricultural Engineering Standards, St Joseph, MI: American Society of Agricultural Engineers, 2000, p. 563.

[6] NIST Handbook 44, "Specifications, tolerances and other technical requirements for measuring device - Grain moisture meters," National Institute for Standards and Technology (NIST), U.S. Department of Commerce, 2015.

[7] United States Department of Agriculture, "Performance-expectations-and tolerances," United States Department of Agriculture - Grain Inspection, Packers and Stockyards Administration, 2017

[8] D. Funk and Z. Gillay, "Unified grain moisture algorithm. UGMA recipe book," United States Department of Agriculture, Grain Inspection, Packers and Stockyards Association (USDA-GIPSA), February 22, 2012

[9] S. Z. Hassen, "Measurement \& error," Dept. of Electrical \& Electronic Engineering, University of Mauritius, 2006.

[10] S. O. Nelson, "Dielectric properties of agricultural products Measurements and applications," IEEE Transactions on Electrical Insulation, vol. 26, no. 5, pp. 845-69, 1991.

[11] A. K. Rai, S. Kottayi, and S. N. Murty, "A low cost field usable portable digital grain moisture meter with direct display of moisture," African Journal of Science and Technology (AJST), vol. 6, no. 1, pp. 97-104, 2005 .

[12] F. Stubsgaard, "Calibration of seed moisture meters," Danida Forest Seed Centre, Technical Note no. 47, University of Copenhagen, 1997.

Copyright (C) 2019 by the authors. This is an open access article distributed under the Creative Commons Attribution License which permits unrestricted use, distribution, and reproduction in any medium, provided the original work is properly cited ( $\mathrm{CC} \mathrm{BY} \mathrm{4.0)}$.

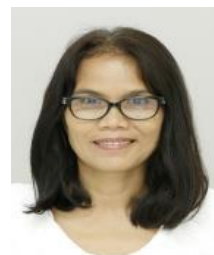

Arlene C. Joaquin is currently a senior science research specialist of the Agricultural Mechanization Division (AMD) of the Philippine Center for Postharvest Development and Mechanization (PHilMech). She completed her bachelor's degree in civil engineering in 1991. In 2007, she was awarded a scholarship and completed her master's degree in agricultural production chain management with specialization in postharvest technology and logistics at Van Hall Larenstein University of Professional Education in the Netherlands. She has received 
numerous awards both in technical papers and technical posters from various technical conferences and national research and development symposia. She is currently involved in a number of research projects in the field of agricultural instrumentation.

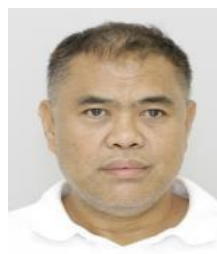

R. C. Martinez is chief science research specialist of the Agricultural Mechanization Division (AMD) of PHilMech. He finished his bachelor's degree in agricultural engineering from the University of the Philippines as cum laude. He completed his master of engineering for postharvest technology at the Asian Institute of Technology in Bangkok, Thailand and was awarded "Hisamatsu Prize", the highest honor given for outstanding conduct of thesis project. With a $\mathrm{PhD}$ degree in agricultural science from the University of Hohenheim in Germany, he was conferred magna cum laude in 2002. A seasoned and competent researcher, he is currently involved in various research projects of AMD.

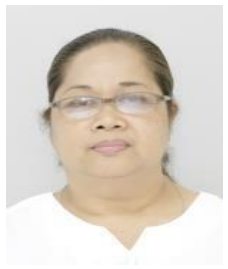

Maria Elizabeth V. Ramos is the team's expert in agricultural economics. She is a graduate of bachelor of science in agricultural economics from the University of the Philippines in Los Banos. An experienced economist, she further her studies with a graduate degree in engineering management to complement her assignment to the Agricultural Mechanization Division (AMD) of PHilMech. 